\title{
Hydraulic modeling of water flow in the thick vadose zone under precipitation
}

\author{
Yu Wang ${ }^{1,3}$, Tonglu Li $i^{1,3^{*}} \mathbb{B}$, Xiaokun Hou ${ }^{1,3,4}$, Yaguo Zhang ${ }^{2,3}$ and Ping Li $\mathrm{Li}^{1,3}$
}

\begin{abstract}
Data from field monitoring and artificial rainfall experiments suggest that the thick vadose zone can be divided into two sub-zones based on soil water variation, namely the active and steady zones. The soil water content of the top active zone (2-5 $\mathrm{m}$ depth) is sensitive to precipitation and evaporation and dominated by transient water flow. Soil water content of the underlying steady zone remains constant over time and there is a steady flow under the force of gravity. However, since the transition from transient flow to steady flow is difficult to observe in nature, the physical mechanism of this transition remains poorly understood. This study establishes a hydraulic model to visually demonstrate water flow in the entire vadose zone under multiple infiltration events. The model comprises of a series vertically aligned water tanks, each with a small outlet at the bottom, and each representing a soil unit. The water level in a tank represents the water content and the related permeability of the soil unit. The results of an experiment conducted with the model clearly show that transient flow in the upper active zone will transfer to steady flow. A zoomed out data with an annual rainfall record at a site in the central Chinese Loess Plateau is applied in the model to simulate the water content and the flow state of the vertical profile, and the results are in accordance with in-situ monitoring data. The outcomes of this study suggest that although water content in the steady zone remains unchanged, there is a constant steady flow seeping downward through the zone, acting as a typical source of groundwater recharge in the loess region.
\end{abstract}

Keywords: Vadose zone, Hydraulic model, Transient flow, Steady flow, Unsaturated loess

\section{Introduction}

The lower loess layer is naturally higher than a nearby riverbed due to its origin through wind mobilization of sand and the entire Loess Plateau is composed of a series of independent hydrogeological units bounded by river valleys (Xu et al. 2020; Wang et al. 2017). Under natural condition, rainfall is typically the only source of groundwater recharge in the Chinese Loess Plateau. However, the mode for rainwater infiltration through the thick vadose zone between preferential flow and piston flow remains contentious ( $\mathrm{Li}$ et al. 2017; Wang et al. 2018). This disagreement stems from the intuitive observation

\footnotetext{
*Correspondence: dcdgx08@chd.edu.cn

${ }^{1}$ Department of Geological Engineering, Chang'an University,

Xi'an 710054, Shaanxi, China

Full list of author information is available at the end of the article
}

of water seepage along the joints and cracks in the loess profile. The argument for piston flow was due to many field observations and artificial rainfall experiments had shown that the depth of the wetting front in loess was limited, generally around $2 \mathrm{~m}$ and no more than $4 \mathrm{~m}(\mathrm{Li}$ et al. 2016; Tu et al. 2009; Xu et al. 2011). Studies based on long-term monitoring in the Chinese Plateau by Hou et al. $(2017,2019,2020)$ and Zhang et al. (2014) found that the depth at which soil moisture was most sensitive to rainfall and evaporation-transpiration was only $2.0 \mathrm{~m}$, whereas water content below $2.0 \mathrm{~m}$ remained constant over time. Figure 1 shows the results of up-to-date data. The monitored data for the Bet Dagan and Rio Galeria basins similarly demonstrated that the response of soil water content to precipitation events began to weaken at a depth exceeding $0.3 \mathrm{~m}$, regardless of whether the response was measured during the dry season or rainy
Springer Open

C The Author(s) 2022. Open Access This article is licensed under a Creative Commons Attribution 4.0 International License, which permits use, sharing, adaptation, distribution and reproduction in any medium or format, as long as you give appropriate credit to the original author(s) and the source, provide a link to the Creative Commons licence, and indicate if changes were made. The images or other third party material in this article are included in the article's Creative Commons licence, unless indicated otherwise in a credit line to the material. If material is not included in the article's Creative Commons licence and your intended use is not permitted by statutory regulation or exceeds the permitted use, you will need to obtain permission directly from the copyright holder. To view a copy of this licence, visit http://creativecommons.org/licenses/by/4.0/. 


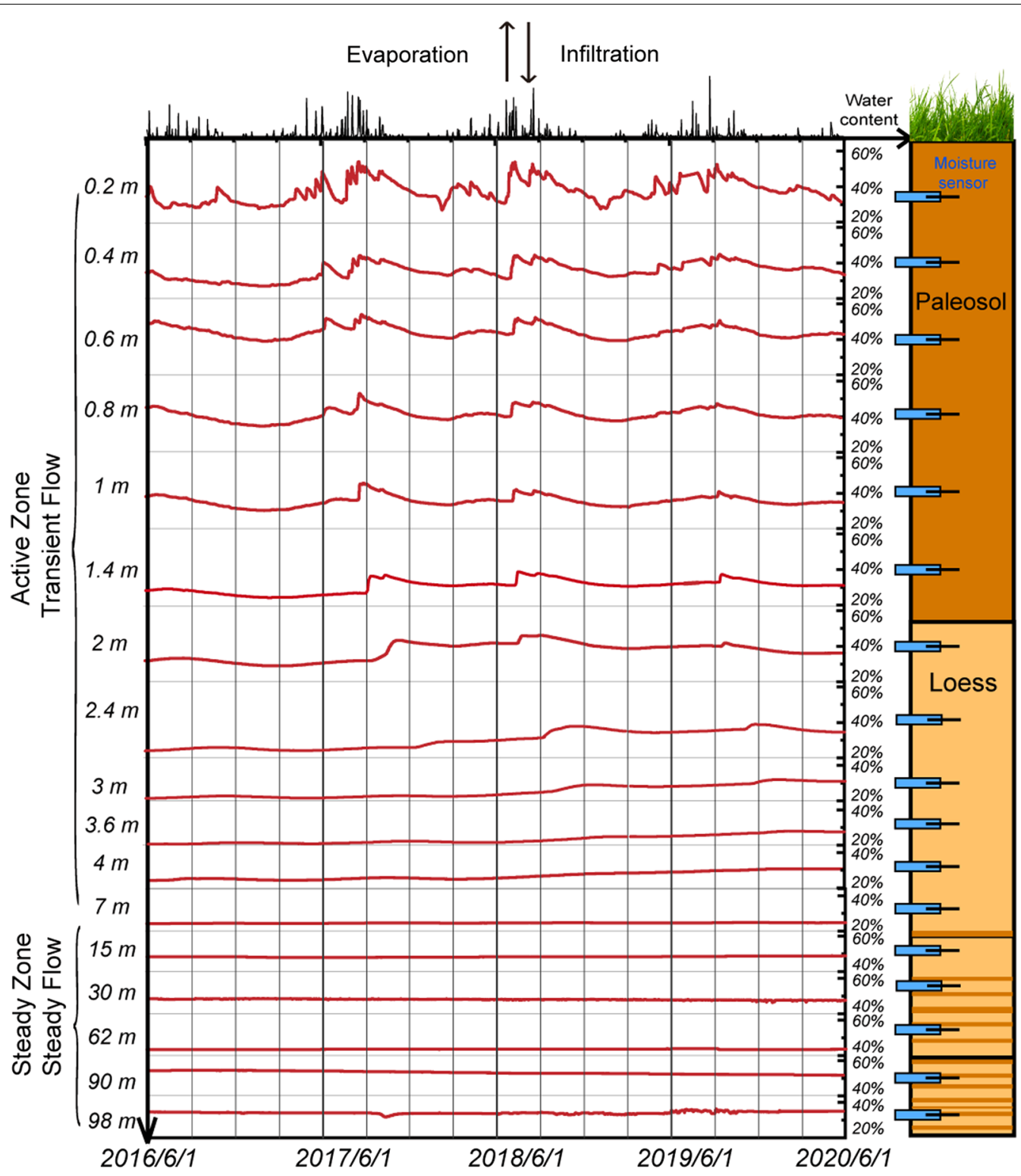

Fig. 1 Conceptual diagram representing two regions of the unsaturated zone

season, and water content remained basically unchanged at a depth exceeding $1 \mathrm{~m}$ (Russo and Fiori 2008). The upper wetting zone is commonly referred to as the "active zone", whereas the underlying zone with an unchanged water content is referred to as the "steady zone". Past scientific understanding had been that piston flow occurred in the active zone, whereas there was no flow in the steady zone (Gazis and Feng 2004).

On the other hand, deep vertical joints, larger root pores and animal holes were widely spread in loess slopes (Derbyshire 2011; Zhang and Liu 2010; Zhuang et al. 2017), which motivated for the theory that rainwater rendered to flow along the joints, pores, and holes, referred to as "preferential flow". However, to date, field observations and measurements have not supported this assumption. Wu et al. (2011) conducted in-situ infiltration tests across fractures in loess ground and did not identify a hydraulic connection between flow in wide fissures and groundwater. A study by Xu and Zhao (1993) on rainfall seepage in an excavated profile with fissures suggested that fissures and macro-pores did not play a key role in water diversion. The vague understanding of preferential flow can be attributed to confusion over the condition of saturation and unsaturation. It is easy 
to demonstrate that preferential flow occurs in saturated soil. But in unsaturated soils, the macro spaces, such joints, large pores and holes, have zero potential while the micro pores have potential. The smaller pore typically has a lower potential. Consequently, water will fill the minor pores first, then expand the bigger ones in order. During the heavy rain period, a saturated zone can temporarily form in shallow ground, with preferential flows forming along some macro paths. However, the preferential flow in macro pores diminishes immediately when saturated flow changes to unsaturated flow.

Loess is a typical unsaturated soil which is sensitive to moisture (Li et al. 2015). Preferential flow occurs temporarily on the ground surface during rain events. Uniform unsaturated seepage, namely piston flow, is the dominant mode of flow in the thick loess vadose zone.

However, it was difficult to observe piston flow in both active and steady zones (Cheng et al. 2018; Basara and Crawford 2010), and this difficulty may have contributed to misunderstanding regarding the existence of flow in the steady zone. The Richards equation described water flow in unsaturated porous media and can help explain this phenomenon (Richards 1931). The use of the Richards equation readily shows that the active zone has transient flow, whereas the steady zone has steady flow. In a natural profile, intermittent rainfall infiltration could form transient flow in the shallow active zone, which transitioned to steady flow in the underlying steady zone (Hou et al. 2017, 2020). Following steady flow, there was a constant flow of water downward to recharge groundwater (Huang et al. 2017, 2020).

The present study uses a hydraulic model by Zhang et al. (2019) to visually demonstrate the transition of water flow from transient flow behavior in the active zone to the steady flow behavior in the steady zone under multiple infiltration events. Furthermore, a differential solution for Richards equation is provided to simulate the flow in the vadose zone under a magnified rainfall series. The result demonstrates the behaviors of water flow in the vadose zone as mentioned above.

\section{The hydraulic model}

Figure 2 is a schematic conceptual representation of the hydraulic model. The model is composed of a set of open water tanks with a small outlet at the bottom of each tank. In the model, a tank represents a soil unit, the tank itself represents the soil skeleton, and the water in the tank represents water in a soil unit. The water-saturated tank represents a saturated soil unit. A set of vertically aligned tanks represents a soil column.

Water supplied to the top tank will successively flow to the tanks below. All tanks have the same cross-section area and height. The water level relative to the height of the tank corresponds to the water content of the soil unit, and the velocity of the change in water level of each tank corresponds to the permeability of the soil unit. The successive flow of water from the top tank to those below reflects the properties of the one-dimensional infiltration process in the vadose zone. The water levels of the tanks should be controlled without overflow to simulate unsaturated flow.

\section{Experiment with the hydraulic model}

As shown in Fig. 3, the experiment was conducted using nine glass tanks vertically fixed onto a wooden board at $10 \mathrm{~mm}$ intervals. Each tank had a diameter and height of

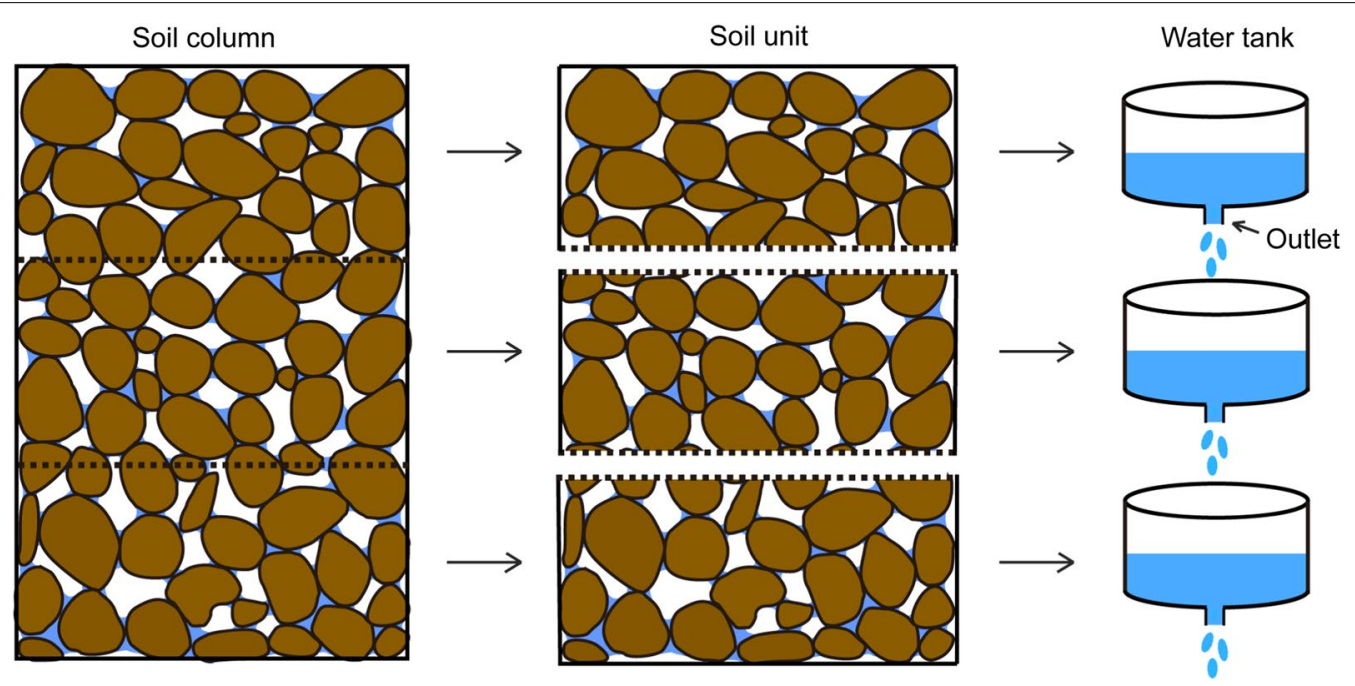

Fig. 2 Representation of a soil column using the hydraulic model in the current study 


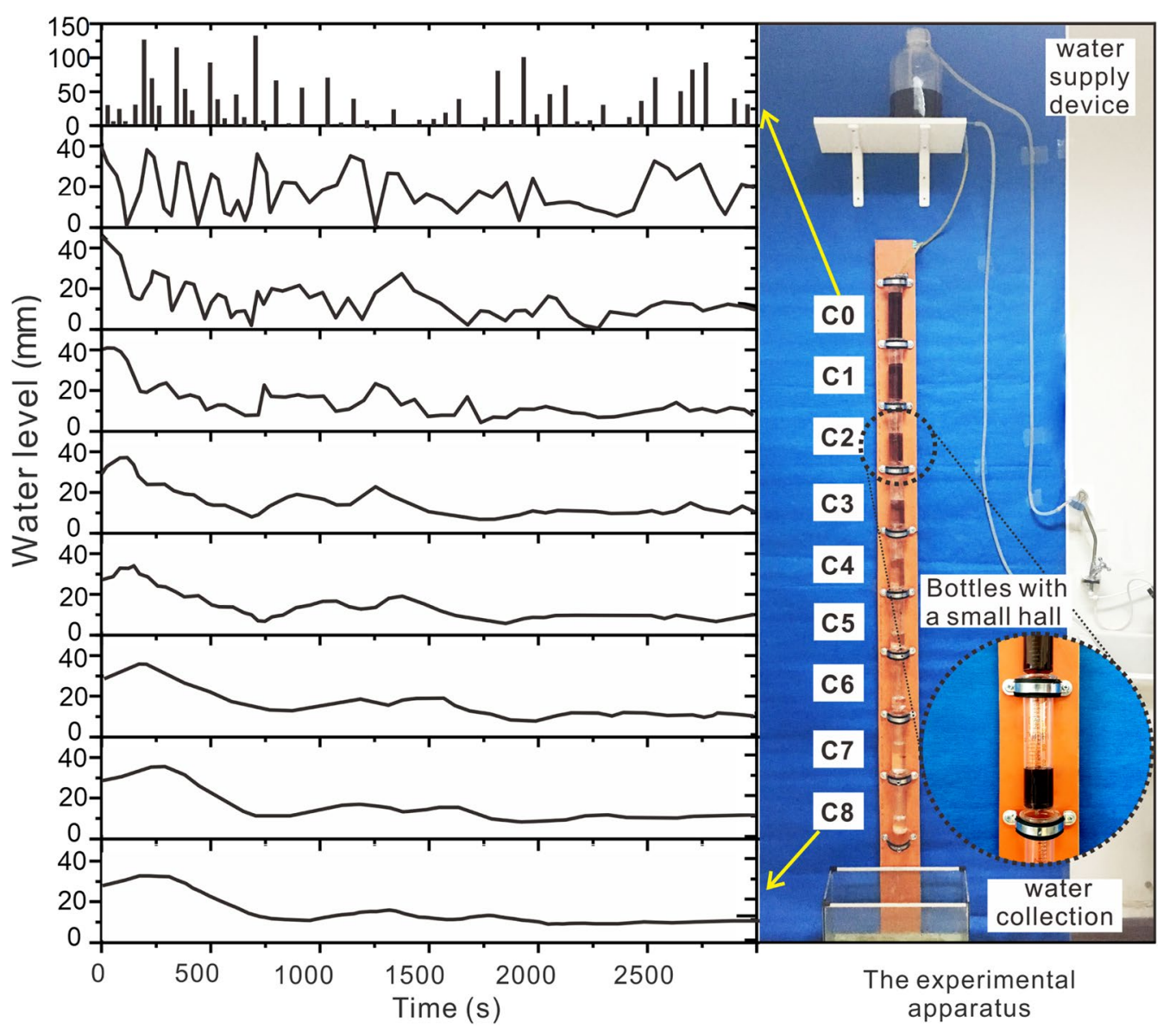

Fig. 3 Water levels in the tanks of the hydraulic model over time under an intermittent supply

$36 \mathrm{~mm}$ and $180 \mathrm{~mm}$, respectively. A water level scale was marked onto the wall of each tank. A water supply bottle connected to a faucet was installed above the tanks. As an initial condition, all tanks had a water level of $30 \mathrm{~mm}$. The boundary condition of the experiment was an intermittent water supply to the top tank $\mathrm{C} 0$ for simulating rainfall events, as shown in the first row in Fig. 3. As the water supply was initiated, the water level of each tank was recorded every $30 \mathrm{~s}$. In total, 3,000 s of data were recorded.

The graphs on the left-hand side of Fig. 3 show water levels of the tanks over time. The water level in $\mathrm{C} 1$ fluctuated widely as a direct response to water supply $\mathrm{C} 0$. The variation in the water level of $\mathrm{C} 2$ was more gentle than that in $\mathrm{C} 1$. An examination of the variation in water level of the tanks from $\mathrm{C} 1$ to $\mathrm{C} 8$ showed that variation in water level progressively decreased from the upper to lower tanks. The water level in the last 2 tanks (C7 and C8) stabilized at $10 \mathrm{~mm}$ after $2000 \mathrm{~s}$. Since the water level of C8 was constant, it could be inferred that any tanks below C8 would also have constant water levels.
The water level changes of different amplitudes in some tanks imply that both the water content and permeability of the soil zone represented by each tank are variable, which reflect the behavior of the active zone with transient flow. Meanwhile, the ones with the constant water level reflect the behavior of the steady zone with a steady flow. The overall profile of the tanks shows a change in the water level from an active zone to a steady zone, which is associated with the transition from transient flow to steady flow.

Since rainfall events are permanent features in nature, the final state in the experiment corresponds to the natural state. The variations in water content in the experiment are consistent with in-situ observations in the soil profile. The experiment conducted in the present study directly demonstrates that there is water flow in both the transient and steady zones. However, this flow is difficult to observe or monitor in a natural soil profile. 


\section{Numerical solution for the hydraulic model}

The present study conducts a theoretical numerical solution for the model to demonstrate the reasons for the ability of the hydraulic model to represent the behavior of unsaturated flow. The following differential expression is deduced from the model (Zhang et al. 2019):

$$
\frac{\Delta q_{i}}{\Delta t}=\frac{\Delta}{\Delta z}\left[k(H)\left(\frac{\Delta H}{\Delta z}-1\right)\right]
$$

In Eq. (1), $q_{i}$ is the ratio of water quantity in the $i$ th tank to the total volume, $z$ is the height of the tank, $H$ is the water head in the tank, and $k(H)$ is equivalent to the hydraulic conductivity function, which is expressed as follows:

$$
k(H)=\frac{r_{i}^{2}}{R^{2}} \sqrt{2 g h_{i}} \frac{\Delta z}{h_{i}+\Delta z}
$$

In Eq. (2), $h_{i}$ is the water level of the $i$ th tank, $r_{i}$ is the outlet radius of the $i$ th tank, $R$ is the radius of the tank, and each tank has the same radius.

The Richards equation (Richards 1931) for vertical onedimensional flow in unsaturated soils is:

$$
\frac{\partial \theta}{\partial t}=\frac{\partial}{\partial z}\left[k(H)\left(\frac{d H}{d z}-1\right)\right]
$$

In Eq. (3), $z$ is the vertical coordinate (downward is positive), $\theta$ is the volumetric water content of soil, $H$ is the pressure head, and $k(H)$ is the hydraulic conductivity function.

Comparing Eqs. (1) and (3) shows their similarity in form and physical context. The left-hand sides of both equations represent the rate of variation in water content to duration, whereas the right-hand sides of both equations, $\Delta H / \Delta z$ or $\partial H / \partial z$, correspond to the hydraulic gradient. $k(H)$ is the function of the water level $h_{i}$ as shown in Eq. (2) and is correlated to the water content $h_{i} / z$ or pressure head $\left(H=-h_{i}\right)$ of the tank. Therefore, $k(H)$ is equivalent to the hydraulic conductivity function, which is also a function of the water content and pressure head.

Substituting Eq. (2) and $q_{i}=h_{i} / z, H=-h_{i}$ into Eq. (1), the first-order differential equation of Eq. (1) for time $t$ and coordinate $z$ can be written as Eq. (4):

$$
h_{i}^{t}=h_{i}^{t-1}+\frac{\sqrt{2 g}}{R^{2}}\left(r_{i-1}^{2} \sqrt{h_{i-1}^{t-1}}-r_{i}^{2} \sqrt{h_{i}^{t-1}}\right) \Delta t
$$

Equation (4) can be used to calculate the water level of each tank from the upper-most tank downward.

The calculation begins from $t=1$. In this case, $h_{i}^{0}(i=1$, $2, \ldots, n$ ) for the right-hand side of Eq. (4) are given as initial conditions, $R$ and $r_{i}$ are fixed, and $g$ is $9800 \mathrm{~mm} / \mathrm{s}^{2}$. Given the boundary condition $h_{0}{ }^{\mathrm{t}}$ at the time intervals $t=k \Delta t(k=1,2, \ldots, \mathrm{m})$, the water level $h_{i}^{\mathrm{t}}$ can be calculated in the order of $h_{1}{ }^{1}, h_{2}{ }^{1}, \ldots, h_{n}{ }^{1} ; h_{1}{ }^{2}, h_{2}{ }^{2}, \ldots, h_{n}{ }^{2} ; \ldots$ $h_{1}{ }^{m}, h_{2}{ }^{m}, \ldots, h_{n}{ }^{m}$. Figure 4 demonstrates the calculation steps.

The outlet radii of the tanks are set as two cases to simulate the flow behaviors in uniform and layered soils, respectively, as shown in Table 1 . In case 1, all tanks have the same outlet radius $r_{i}$, which represents a uniform soil column with the same hydraulic conductivity function among the soil units. In case 2, each tank has a different outlet radius $r_{i}$, which represents a layered soil column with different hydraulic conductivity functions among the soil units. The initial condition of the water content is also set as two states. Under state 1, the water levels of all the tanks are set to zero, whereas under state 2 , the water levels are set according to the values listed in Table 1. The daily rainfall data recorded at the monitoring site in the Central Chinese Loess Plateau, from March 2018 to March 2019, are used as reference data for the boundary condition. The present study applies daily precipitation data, but the time interval of one day is zoomed to $1 \mathrm{~s}$ in the simulation. The long-term effect of water flow in the vadose zone is achieved by repeatedly applying one year of daily precipitation over 5 years. Since the time interval of the experiment is set to $1 \mathrm{~s}$, the total duration of the experiment is 5 cycles of $365 \mathrm{~s}$.

\section{Analysis of the results}

The simulated results are summarized in Fig. 5. The dashed lines indicate the case under which the initial water levels of all tanks are zero, whereas the solid lines indicate the case under which the tanks have different initial water levels. The green lines show the case under which all tanks have the same outlet radius

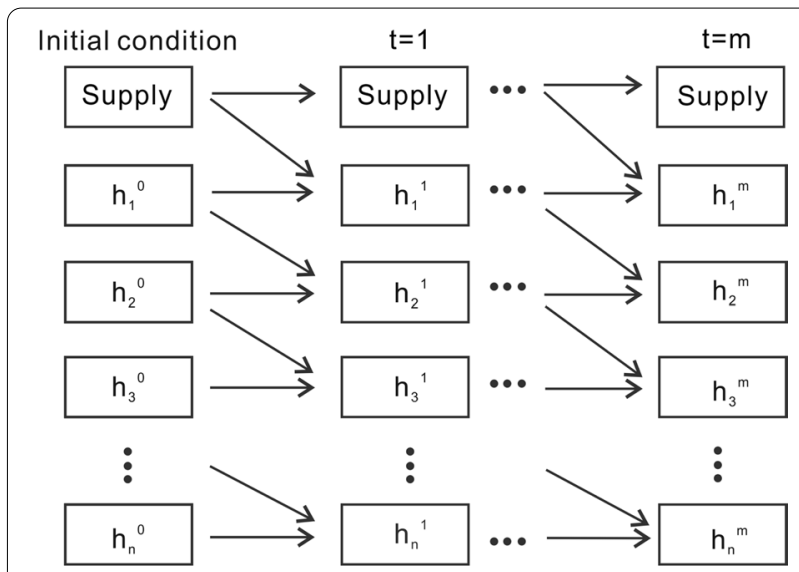

Fig. 4 Flow chart demonstrating the process used to derive the numerical solution for the model 
Table 1 The properties of the model

\begin{tabular}{|c|c|c|c|c|c|c|c|c|c|}
\hline Tank & $\mathrm{C}_{0}$ & $\mathrm{C}_{1}$ & $\mathrm{C}_{2}$ & $\mathrm{C}_{3}$ & $\mathrm{C}_{4}$ & $C_{5}$ & $C_{6}$ & $C_{7}$ & $\mathrm{C}_{8}$ \\
\hline \multicolumn{10}{|l|}{ Initial condition $h_{i}^{0}(\mathrm{~mm})$} \\
\hline State 1 & Rainfall & 0 & 0 & 0 & 0 & 0 & 0 & 0 & 0 \\
\hline State 2 & Rainfall & 0.3 & 0.4 & 0.5 & 0.6 & 0.7 & 0.8 & 0.9 & 1.0 \\
\hline \multicolumn{10}{|l|}{ Outlet radius $r_{\mathrm{i}}(\mathrm{mm})$} \\
\hline Case 1 & 1.80 & 1.70 & 1.70 & 1.70 & 1.70 & 1.70 & 1.70 & 1.70 & 1.70 \\
\hline Case 2 & 1.80 & 1.80 & 1.80 & 1.75 & 1.75 & 1.70 & 1.70 & 1.65 & 1.60 \\
\hline Boundary condition $h_{0}{ }^{\mathrm{t}}(\mathrm{mm})$ & $\begin{array}{l}\text { Daily rainfall; } t_{k}=k \Delta t \\
\Delta t=1 \mathrm{~s},(k=1,2, \ldots, m)\end{array}$ & & & & & & & & \\
\hline
\end{tabular}

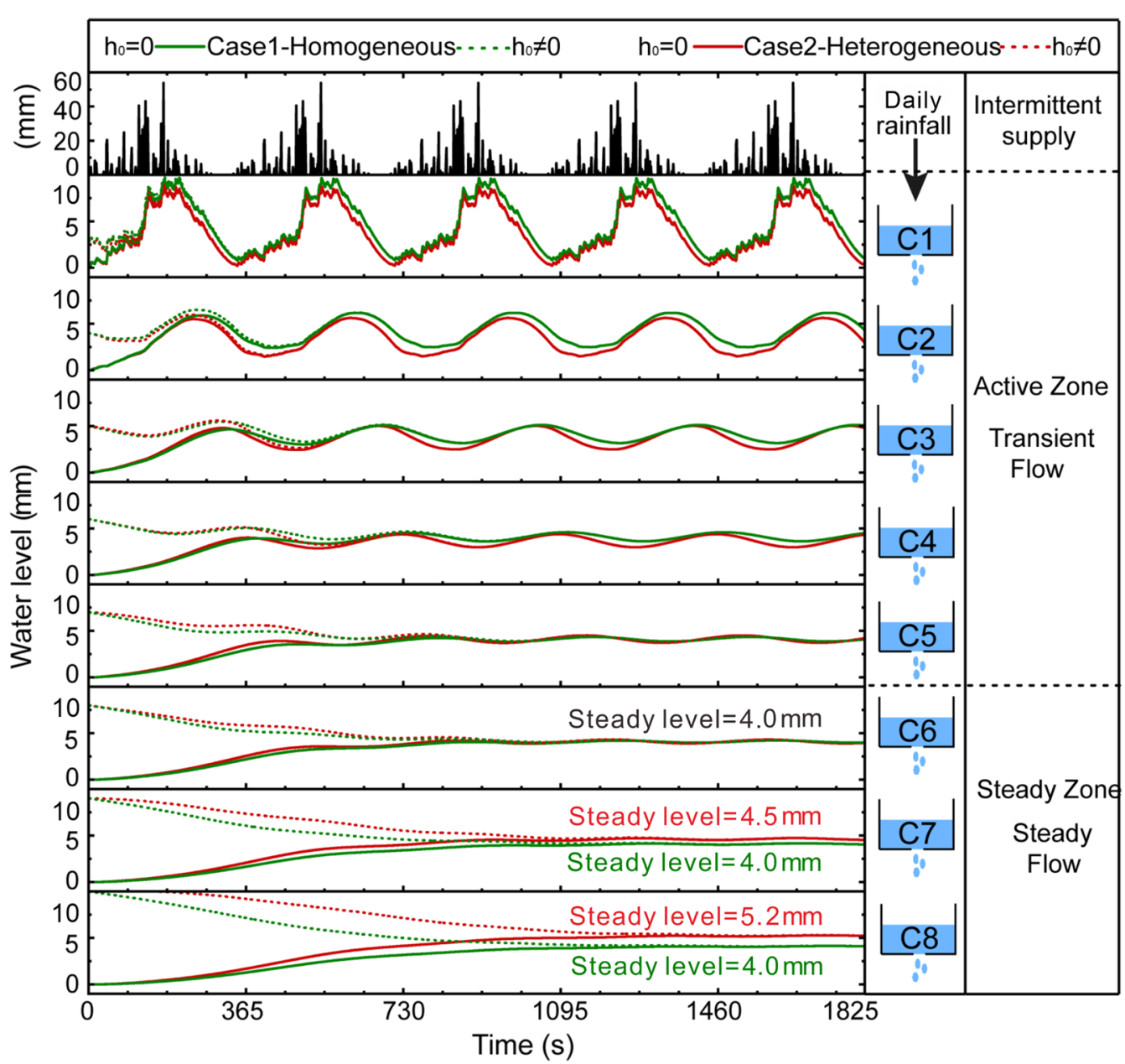

Fig. 5 Change in water level in the system under two cases of initial tank water level

$\left(r_{i}=1.70 \mathrm{~mm}\right)$, whereas the red lines show the case under which each tank has a different outlet radius.

Comparison of the results for an identical initial condition (state 1, zero water level, dashed line) with those generated under different initial conditions (state 2, different water levels, solid line) shows that the final flow state of each tank is independent of the initial condition. Regardless of identical (zero) or different initial water levels, the final water levels of the upper tanks will eventually reach a state of periodic fluctuation, whereas those of the lower tanks tend to stabilize. The dashed line and corresponding solid line eventually converge. However, 
hysteresis can be observed on the curves under which the lower tanks require more time to reach the final state.

Table 1 shows the conditions under which all tanks have the same outlet radius (case 1, green lines) and under which each tank has a different outlet radius (case 2 , red lines). And the simulated results in Fig. 5 show that the tanks with larger outlet radii (case 2, C1 to C4, red lines) have lower water levels, whereas those with smaller outlet radii (case 1, C1 to C4, green lines) have higher levels. The same regularity in water level appears in the $\mathrm{C} 7$ and $\mathrm{C} 8$. Both $\mathrm{C} 7$ and $\mathrm{C} 8$ have higher water levels, whereas they have a smaller and larger outlet radius under case 2 (red lines) and case 1 (green lines), respectively. Tanks with an identical outlet radius (in both cases, C5 and C6) show similar water levels. The green and red line for $\mathrm{C} 5$ and $\mathrm{C} 6$ are close and finally converged. The simulated results reflect the flow behavior in unsaturated soils. A soil layer with good hydraulic conductivity and low water retaining capacity is represented by the tanks with a larger outlet radius, whereas the soil layer with low hydraulic conductivity and high water retaining capacity is represented by tanks with a small outlet radius.

Figure 6 shows the soil water retention curves (SWRC) of the silt and sand, which clearly illustrate the difference in the ability of each of the two soils to retain water. Under the same water content (e.g., 17.5\%), the soil suction of silt $(40 \mathrm{kPa})$ would far exceed that of sand $(2 \mathrm{kPa})$, representing a much lower permeability of the silt.

The variations in the water levels of the tanks tend to decrease from the upper to lower tanks, regardless of their initial condition. The water level in $\mathrm{C} 0$ represents the influence of rainfall events. There is a continuous

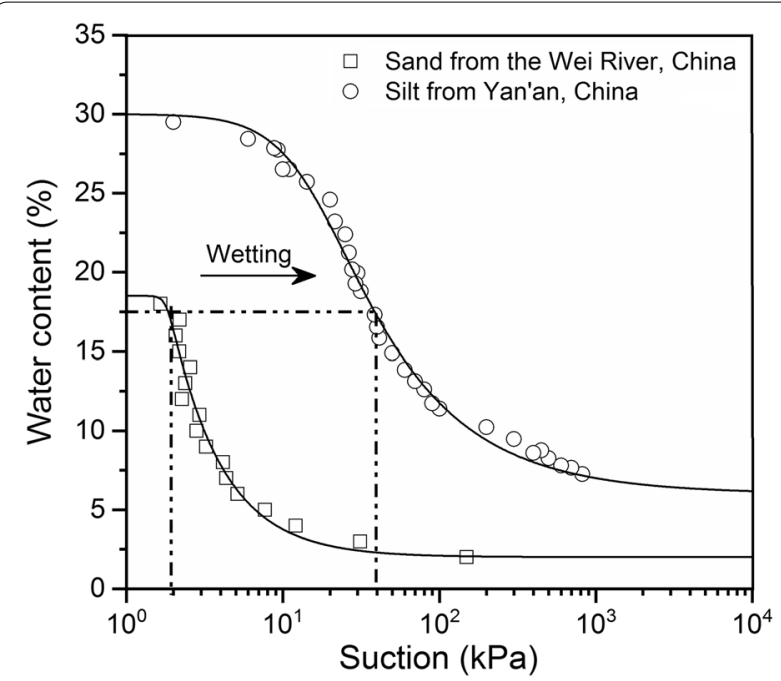

Fig. 6 Representative soil water retention curves (SWRC) of sand and silt from China fluctuation in the water level of $\mathrm{C} 1$, with a short time lag relative to $\mathrm{C} 0$. The water levels in $\mathrm{C} 2$ and $\mathrm{C} 3$ show continuous and smooth fluctuation with a time lag relative to the tanks above, whereas $\mathrm{C} 4$ to $\mathrm{C} 6$ show similar trends in water level variation. The amplitudes of water level in tanks $\mathrm{C} 1$ to $\mathrm{C} 6$ rapidly decrease from the top tank to the bottom tank. The water levels of $\mathrm{C} 7$ and $\mathrm{C} 8$ eventually reach a steady state. As mentioned above, the final water levels of the tanks are independent of initial conditions. Based on the final state, the model column can be divided into two zones, namely the active zone and the steady zone.

The water levels in the active zone are influenced by the boundary condition, whereas those in the steady zone are constant with a steady water flow. The flow velocity of each tank in the steady zone is equal to the average boundary recharge. As demonstrated by the monitoring results shown in Fig. 1, the flow behaviors simulated by the model are similar to those observed in natural soil layers. The hydraulic model provides strong evidence for the existence of steady flow, which acts as a typical source of groundwater recharge in the loess region.

\section{Discussion}

Figure 7(a) shows the in-situ monitoring results of water content of the soil profile in the central Chinese Loess plateau (Hou et al. 2020). Figure 7(b) shows the simulated results using the monitored precipitation data. The simulated water content of the soil profile is consistent with the observed water content. The mechanism of the similarity between the results of the physical model and the natural situation is discussed below.

To solve Eq. (3), two key soil constitutive functions should be provided in advance, namely the SWRC and hydraulic conductivity function (HCF) (Fredlund 2006; $\mathrm{Lu}$ and Likos 2006). These functions can use the empirical equations, such as the commonly used SWRC and HCF equations provided by van Genuchten (1980) and Fredlund et al. (1994), and the parameters should be fitted using laboratory test data. The equivalent SWRC and HCF for the hydraulic model can be deduced based on the principle of the model. Supposing that the equivalent SWRC is expressed as equivalent matric suction against the degree of saturation and that HCF is expressed as the equivalent hydraulic conductivity against the degree of saturation, then the water level height of the $i$ th tank is $h_{i}$, and its degree $\left(S_{i}\right)$ of saturation is:

$$
S_{i}=\frac{h_{i}}{\Delta z}
$$

The equivalent matric suction $\left(\psi_{i}\right)$ is: 


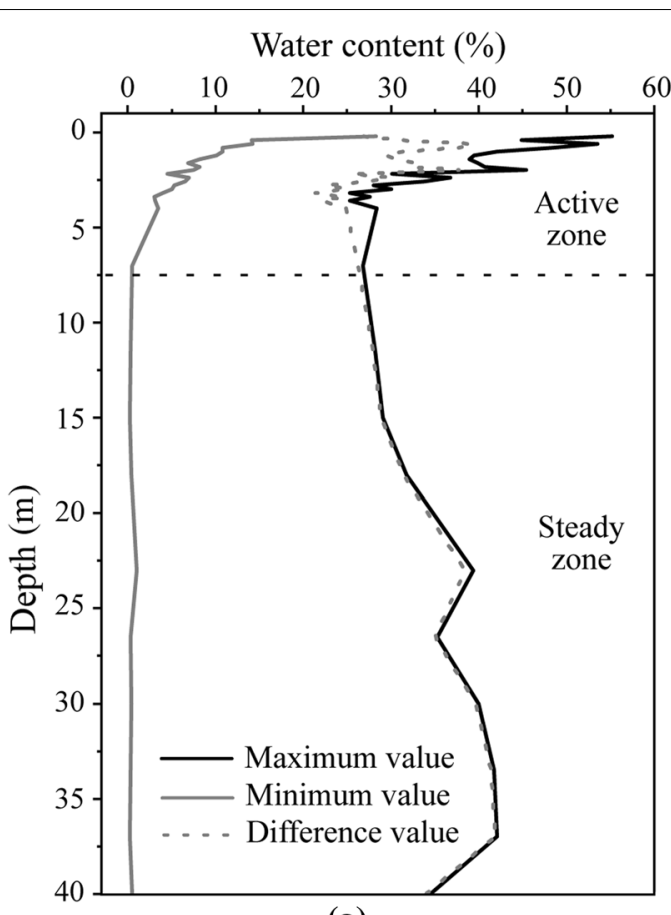

(a)

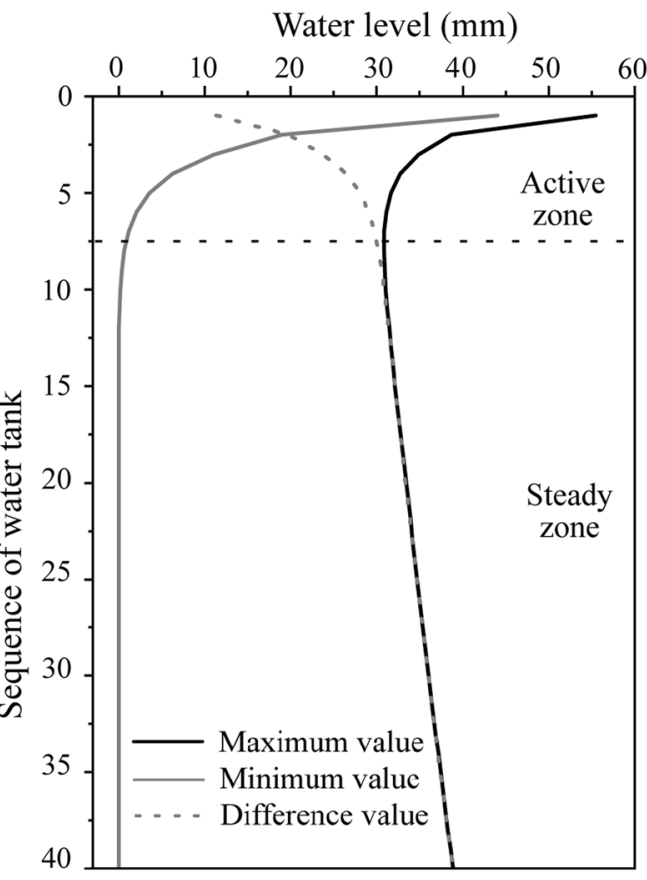

(b)

Fig. 7 Comparison of soil water content and calculated value using rainfall data

$$
\psi_{i}=\Delta z-h_{i}
$$

Therefore, the equivalent SWRC of the tank is

$$
\psi_{i}=\left(1-S_{i}\right) \Delta z
$$

From Eqs. (2) and (5), the equivalent HCF of the tank can also be easily obtained:

$$
k\left(S_{i}\right)=\frac{r_{i}^{2}}{R_{i}^{2}} \sqrt{2 g S_{i} \Delta z} \frac{1}{S_{i}+1}
$$

Suppose $\Delta z$ is unity, then Eqs. (7) and (8) can be simplified to:

$$
\begin{aligned}
& \psi_{i}=1-S_{\mathrm{i}} \\
& k\left(s_{i}\right)=\frac{r_{i}^{2}}{R_{i}^{2}} \sqrt{2 g S_{i}} \frac{1}{S_{i}+1}
\end{aligned}
$$

Figure 8 shows the curves of Eqs. (9) and (10). Equation (9) is a linear function in which the equivalent matric suction linearly increases with decreasing saturation, similar to the trend in SWRC variation for real soil. However, it is difficult to fit a linear SWRC function for real soil. In addition, Eq. (10) shows that the trend of HCF is similar to that of real soil. However, the HCF cannot be applied in real soils. The advantage of the model is that

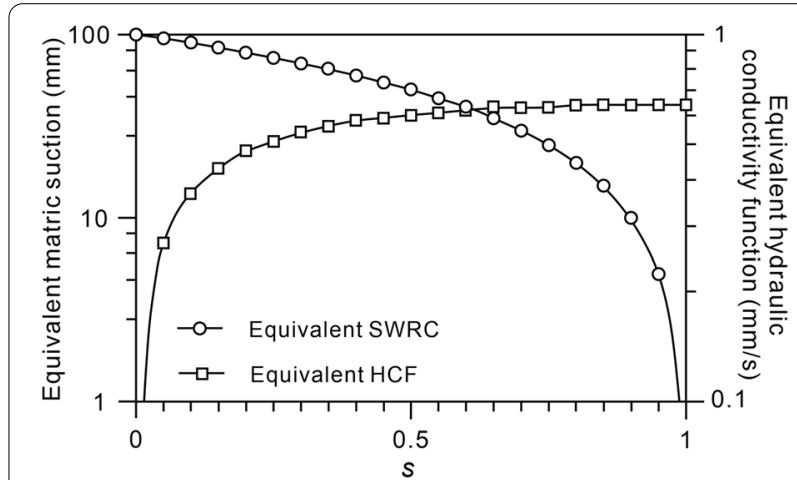

Fig. 8 Equivalent matric suction and hydraulic conductivity function against degree of saturation of the model

it can visually show the two-dimensional profile of water flow in the vadose zone and can help to clarify the argument between piston flow and preferential flow.

\section{Conclusions}

The paper uses a hydraulic model to simulate the flow behavior in the vadose zone. The mathematical expression of the hydraulic model is deduced and is similar to the Richards governing equation. The experiment and mathematical solutions demonstrate that under a condition of intermittent precipitation events, the model 
column can be divided into two zones, namely active zone and steady zone. The water content in the active zone changes the variation of the boundary conditions (e.g., precipitation, evaporation in natural conditions), whereas it keeps constant in the steady zone. The results of the model are consistent with the soil water content profile observed in the field. The model can overcome the difficulty of observing unsaturated flow in nature by visually demonstrating the two-dimensional profile of water flow in both the active and steady zones, and particularly the transition from transient water flow to steady flow.

\section{Acknowledgements}

The author would like to thank the National Natural Science Foundation of China for its funding and trust.

\section{Authors' contributions}

Yu Wang was involved in the design and operation of experiment, data collection and analysis, simulations and writing the manuscript. And all other author contributed in operation of experiment, data analysis, simulations and writing the paper. All authors read and approved the final manuscript.

\section{Funding}

The study was supported by the National Natural Science Foundation of China (Grant Nos. 41772278, 41790442, 41807242). The above financial support is gratefully acknowledged.

\section{Availability of data and materials}

Some or all data, models, or code that support the findings of this study are available from the corresponding author upon reasonable request.

\section{Declarations}

\section{Competing interests}

The authors declare that they have no competing interests.

\section{Author details}

'Department of Geological Engineering, Chang'an University, Xi'an 710054, Shaanxi, China. ${ }^{2}$ Department of Civil Engineering, Chang'an University, Xi'an 710054, Shaanxi, China. ${ }^{3}$ Water Cycle and Geological Environment Observation and Research Station for the Chinese Loess Plateau, Ministry of Education, Lanzhou 745399, Gansu, China. ${ }^{4}$ Key Laboratory of Shale Gas and Geoengineering, Institute of Geology and Geophysics, Innovation Academy for Earth Science, CAS, 10029 Beijing, China.

Received: 12 May 2021 Accepted: 14 February 2022

Published online: 28 February 2022

\section{References}

Basara JB, Crawford TM (2010) Improved installation procedures for deep-layer soil moisture measurements. J Atmos Oceanic Tech 17(6):879-884

Cheng Y, Zhan H, Yang W, Fang B (2018) Deep soil water recharge response to precipitation in mu us sandy land of china. Water Sci Eng 11(2):8

Derbyshire E (2011) Geological hazards in loess terrain, with particular reference to the loess regions of China. Earth Sci Rev 54(1-3):231-260

Fredlund DG (2006) Unsaturated soil mechanics in engineering practice. J Geotech Geoenviron Eng 132(3):286-321

Fredlund DG, Xing A, Huang S (1994) Predicting the permeability function for unsaturated soils using the soil-water characteristic curve. Can Geotech J 31(4):533-546

Gazis C, Feng X (2004) A stable isotope study of soil water: evidence for mixing and preferential flow paths. Geoderma 119(1-2):97-111
Hou X, Vanapalli SK, Li T (2017) Water infiltration characteristics in loess associated with irrigation activities and its influence on the slope stability in heifangtai loess highland, china. Eng Geol 234:27-37

Hou X, Li T, Vanapalli SK, Xi Y (2019) Water percolation in a thick unsaturated loess layer considering the ground-atmosphere interaction. Hydrol Process 33(5):794-802

Hou X, Vanapalli SK, Li T (2020) Water flow in unsaturated soils subjected to multiple infiltration events. Can Geotech J 57(3):366-376

Huang T, Pang Z, Liu J, Ma J, Gates John (2017) Groundwater recharge mechanism in an integrated tableland of the Loess Plateau, northern China: insights from environmental tracers. Hydrogeol J 25(7):2049-2065

Huang T, Ma B, Pang Z, Li Z, Li Z, Long Y (2020) How does precipitation recharge groundwater in loess aquifers? Evidence from multiple environmental tracers. J Hydrol 583:124532

Li P, Zhang X, Shi H (2015) Investigation for the initiation of a loess landslide based on the unsaturated permeability and strength theory. Geoenviron Disast 2(1):24

Li P, Li T, Vanapalli SK (2016) Influence of environmental factors on the wetting front depth: a case study in the Loess Plateau. Eng Geol 214:1-10

Li Z, Chen X, Liu W, Si B (2017) Determination of groundwater recharge mechanism in the deep loessial unsaturated zone by environmental tracers. Sci Total Environ 586:827-835

Lu N, Likos WJ (2006) Suction stress characteristic curve for unsaturated soil. J Geotech Geoenviron Eng 132(2):131-142

Richards AL (1931) Capillary conduction of liquids through porous mediums. Physics 1(5):318-333

Russo D, Fiori A (2008). Equivalent vadose zone steady state flow: an assessment of its capability to predict transport in a realistic combined vadose zone-groundwater flow system. Water Resour Res 44(9)

Tu XB, Kwong AKL, Dai FC, Tham LG, Min H (2009) Field monitoring of rainfall infiltration in a loess slope and analysis of failure mechanism of rainfallinduced landslides. Eng Geol 105(1-2):134-150

Van Genuchten MT (1980) A closed-form equation for predicting the hydraulic conductivity of unsaturated soils. Soil Sci Soc Am J 44(5):892-898

Wang H, Li M, Zhou B, Zhou Y, Yuan Z, Chen Y (2017) Application of a hybrid model of neural networks and genetic algorithms to evaluate landslide susceptibility. Geoenviron Disast 4(1):15

Wang J, Li P, Ma Y, Li T (2018) Influence of irrigation method on the infiltration in loess: field study in the Loess Plateau. Desalin Water Treat 110(APR.):298-307

Wu C, Xu L, Dai F, Min H, Tham LG, Kwong AKL, Zhou YF (2011) Topographic features and initiation of earth flows on Heifangtai loess plateau. Rock Soil Mech 32(06):1767-1773 (in Chinese)

Xu Z, Zhao Y (1993) Research of fractural efficacy on mechanisms governing water flow in unsaturated loess. J Changchun Univ Earth Sci 23(03):326329 (in Chinese)

Xu L, Dai FC, Tham LG, Tu XB, Min H, Zhou YF, Xu K (2011) Field testing of irrigation effects on the stability of a cliff edge in loess, North-West China. Eng Geol 120(1-4):10-17

Xu P, Zhan Q, Qian H, Yang F, Zheng L (2020) Investigating the mechanism of ph effect on saturated permeability of remolded loess. Eng Geol 284(6):105978

Zhang M, Liu J (2010) Controlling factors of loess landslides in western China. Environ Earth Sci 59(8):1671-1680

Zhang C, Li T, Li P (2014) Rainfall infiltration in Chinese loess by in situ observation. J Hydrol Eng 19(9):06014002

Zhang Y, Li T, Shen W, Wang Y (2019) Hydraulic model of transition of transient to steady flows in the Vadose zone. J Hydrol Eng 24(12):04019052

Zhuang J, Peng J, Wang G, labal J, Wang Y, Li W, Zhu X (2017) Prediction of rainfall-induced shallow landslides in the Loess Plateau, Yan'an, China, using the TRIGRS model. Earth Surf Proc Land 42(6):915-927

\section{Publisher's Note}

Springer Nature remains neutral with regard to jurisdictional claims in published maps and institutional affiliations. 